\section{O caos urbano e a poética das cidades: um estudo de mídia, cotidiano e sociabilidade}

RESUMO

Este trabalho é a atualização de um capítulo da tese Dionísio na Idade Média, defendida no Doutorado de Ciências Sociais, na Universidade René Descartes, Paris V, Sorbonne, no inverno de 1995, sob orientação de Michel Maffesoli. Seguimos as pistas que podem estimular uma interpretação das tendências contemporâneas na cultura brasileira, incluindo a música urbana, a moda, a publicidade, o cinema e a televisão. É um estudo que sugere enfoques pertinentes para as pesquisas sobre comunicação e linguagem, primeiramente porque trata das narrativas que traduzem e performatizam 0 cotidiano, as telenovelas. Privilegiamos, sobretudo, um olhar voltado para os modos de comunicação e sociabilidade, para as interações e vinculações experimentadas pelos indivíduos na era da informação.

\section{ABSTRACT}

This article discusses some of the contemporary tendencies which might be exerting their influence on Brazilian culture, in fields such as urban music, fashion, advertising, film and television. It also sugests an approach to study communication and language, as well as communication and sociability, through soap operas and daily interactions.

\section{PALAVRAS-CHAVE (KEY WORDS) \\ - Cultura (Culture) \\ - Comunicação (Communication) \\ - Socialidade (Sociability)}

\section{Cláudio Cardoso de Paiva}

Departamento de Comunicação - Univ. Federal da Paraíba

\section{Introdução}

EM NOSSO TRABALHO SEGUIMOS as pistas que podem estimular uma interpretação das tendências contemporâneas na cultura brasileira, incluindo a música urbana, a moda, a publicidade, o cinema e a televisão, entre outros temas. É um estudo que sugere enfoques empíricos pertinentes para as pesquisas sobre comunicação e linguagem porque trata de narrativas que traduzem e performatizam o cotidiano, ou seja, as telenovelas. Mas privilegiamos, sobretudo, um olhar voltado para os modos de comunicação e sociabilidade, para os tipos de interações e vínculos entre os indivíduos, na chamada era da informação. Exercitamos um estudo atento às formas de pensar, dizer e agir do atores sociais captando a modulação dos seus desejos e representações coletivas. Tudo isso se presta a um olhar sobre as mídias, particularmente sobre a televisão que focaliza o "vivo do sujeito" e suas inscrições no plano da ficção, e ao mesmo tempo, na dimensão do real histórico.

Como o verso ou o reverso da fisionomia brasileira, a televisão apresenta visões e estimula percepções do Brasil, justificando por isso um exame mais rigoroso.

Este texto, especificamente, busca discutir o tema das culturas urbanas e suas interfaces, incluindo as imagens da televisão, que exibem um farto repertório da diversidade cultural contemporânea. Com este fim, elegemos um recorte de imagens da ficção seriada televisiva, como pretexto para examinar alguns detalhes 
da complexidade cultural brasileira. Observamos que os meios de comunicação e a circulação dos seus produtos na ambiência cotidiana disseminam um universo paralelo, que se cola à realidade como uma segunda pele do Brasil; algumas vezes, envolve e fascina os indivíduos como uma espécie de paraíso artificial, há momentos, porém, que aparece como visão assombrosa, cavando mais fundo o horror dos abismos sociais.

Dispondo de um forte arsenal de imagens mitológicas, a ficção brasileira revela dimensões importantes dos desejos e das representações coletivas, que nos permitem apreender os estilos de experiências dos sujeitos. A televisão, por meio das telenovelas, abre as janelas para uma contemplação dos diversos campos da atividade pragmática. Os tipos de comportamento, os afetos, a ira, o ódio, as formas de exclusão ou, num sentido oposto, os vínculos sociais, as formas do contrato social, o conforto dos laços sentimentais; tudo isso se faz presente no mundo de simulacros produzidos pela ficção seriada na TV.

A televisão irradia as imagens de um país contendo os traços de desenvolvimento industrial-tecnológico e contrastando com as imagens de um "outro país", que parece se erguer sobre escombros e ruínas. Nesse ambiente, proliferam os objetos tecnológicos, como extensões dos indivíduos, produzindo um efeito de simulação dos signos de prosperidade, num ambiente social que não usufrui eqüitativamente dos benefícios desse novo mundo.

Em verdade, toda a experiência cultural tem sido alterada pela introdução das modificações técnicas nos hábitos da sociedade. Ocorre hoje um processo análogo ao das épocas históricas anteriores, com os adventos do alfabeto, da imprensa, da máquina a vapor e da energia elétrica. Os novos artefatos, como o celular, o controle remoto, o computador e os seus modos de usar, na cultura emergente, prefiguram uma nova ecologia urbana, em que natureza e cultura parecem se justapor, modificando sensivelmente as estruturas da vida cotidiana. Tais mudanças promovem instabilidade, pois implicam uma desconstrução da ordem, além de ocorrer de maneira desigual e desequilibrada, pois não vêm para todos. Mas por outro lado, geram novas formas de agregação e sociabilidade, imprimindo novos hábitos de vivência comunitária, e propiciam estratégias de politização do cotidiano, produzindo, inclusive, novas maneiras de exercer a subjetividade e a cidadania.

A televisão, como uma fábrica de consensos, simula modos de identidades e identificações, e mesmo de maneira provisória pode estimular o glamour e a fascinação, mas também pode gerar estereótipos e estigmas, reforçando antigos preconceitos ${ }^{1}$.

Na pressa em exibir a diversidade da sociedade global, a mídia corre o risco de construir simulacros deturpados e acelerar as formas de desprezo e intolerância para com o outro. Muitas telenovelas têm se caracterizado pela maneira estereotipada e pelo modo como derrapa na "apresentação" das diferenças e especificidades ontológicas e regionais, reforçando, muitas vezes, antigos preconceitos. Assim, os clichês do nordestino, do gay, do pobre, do estrangeiro, tais como as exibições negativas do caipira, do negro e do índio, etc. são angulações equivocadas, consistindo em formas "reativas" que se disseminam pelo circuito dos meios de comunicação².

Isso não consiste numa surpresa porque a telenovela, enquanto um produto massivo que refrata a "polifonia de vozes" das camadas populares, tende a absorver e reproduzir também as visões de mundo preconceituosas e excludentes. Isto é, a telenovela, como, aliás, a maioria dos produtos da cultura popular de massa, reflete (e muitas vezes reforça) a ética e a estética de uma sociedade cujos referenciais desmoronaram e cujos 
indivíduos apostam numa "lógica do pior". Os sujeitos se sentem excluídos numa sociedade cada vez mais competitiva, em que Ihes faltam educação, segurança, condições básicas de sobrevivência, em que as chances de autonomia e participação social são mínimas, e então se apegam às formas vis do preconceito e da discriminação. Neste contexto, tudo aquilo que não se inclui na lógica da modernidade e do desenvolvimento global, no mar de rosas da civilização tecnológica irradiada pela estética da mídia, aparece como degenerado, como "pior". Isto consiste num aspecto da ficção, que apresenta os tipos regionais a partir de algumas noções que já são clichês e se distanciam de uma representação dos indivíduos e grupos étnicos, religiosos ou raciais com todas as suas idiossincrasias, riquezas e complexidades. A disposição para compor um retrato naturalista da paisagem multiforme do Brasil, com todas as suas cores, credos e raças, escorrega muitas vezes num tipo de populismo que desenterra antigos preconceitos. Em suma, na ânsia de executar uma produção bem-sucedida, na predisposição para realizar uma mímese da realidade brasileira, apoiada em padrões externos à realidade do país, a mídia muitas vezes reconstrói um real invertido e projeta uma simulação infeliz da sociedade sob a forma do politicamente travado; assim, em vez de representar as nossas singularidades, as diferenças e combinações específicas que possibilitam o estilo do nosso espírito comunitário, a mídia nos torna "estranhos a nós mesmos", como escreve, num outro registro, Júlia Kristeva ${ }^{3}$.

Por outro lado, há telenovelas inteligentes em que os personagens aprenderam a rir de suas próprias tragédias e a desmontar toda a mitificação dos padrões de comportamento e modelos de existência. Partindo de uma perspectiva dialógica ${ }^{4}$, buscando entender a diversidade cultural, percebemos que as telenovelas se realizam também a partir da percepção sensível de intelectuais, poetas, artistas, estetas, cuja compreensão, atenta para a leveza dos seres, na rede complexa das grandes cidades, permite uma aproximação da alma atômica dos sujeitos e suas formas de interação com o outro. Em meio ao amplo repertório da ficção brasileira, podemos detectar produções de qualidade que se marcam pelo cuidado no tratamento das sensibilidades, das formas de sociabilidade e comunicabilidade que agregam os indivíduos e suas tribos numa paisagem cultural marcada pela permanente transformação.

Há telenovelas e minisséries, por exemplo, que se caracterizam pelo refinamento como mostram o caos e a poética das cidades. Já é possível vislumbrar uma série de programas, cujas aparições se revelam como obras de arte à disposição das massas. Já mencionamos a riqueza do farto material produzido pela ficção, a partir da adaptação talentosa de obras literárias para a linguagem do vídeo; os exemplos são inúmeros e se evidenciam, principalmente, por meio das minisséries ${ }^{5}$. Mas, a ficção televisiva também tem realizado trabalhos a partir de roteiros originais que superam as divisões arbitrárias, os preconceitos e as discriminações dos tipos regionais, de etnia, de gênero e de classe, e apresentam, de modo sublime, a organicidade e a parte vitalista da sociedade. Reafirmamos que as ficções televisivas, apesar do empenho em fabricar um produto pronto para o consumo fácil, apresentam obras que emanam de uma imaginação criadora, apoiando-se nas figuras e mitos ancestrais, que revigoram a partilha social das imagens e geram formas inéditas de sociabilidade ${ }^{6}$. Pelo viés das mitologias e da sua atualização na sociedade de consumo, procuramos discutir como as ficções reconstroem as formas de identificação dos sujeitos, seus modos de sociabilidade e suas inscrições nas experiências do cotidiano.

2 Mitologias e laços comunitários 
No livro Máquina de Narciso ${ }^{7}$, o teórico da comunicação Muniz Sodré propõe uma questão instigante, que leva o leitor a pensar: "Se os gregos tinham um tipo de conhecimento que lhes permitiria um desenvolvimento tecnológico, tal qual o conhecemos hoje, por que não o fizeram?" Essa é uma indagação que vem a calhar em nossos estudos sobre mídia, cotidiano e sociabilidade. Em primeiro lugar, os gregos tinham uma consideração particular pelo cuidado com o corpo e suas relações sociais eram marcadas pelo calor da proximidade; seria estranho imaginá-los, por exemplo, no exercício do namoro virtual, como fazem hoje os indivíduos conectados à Internet. Depois, a "provocação amistosa" de Muniz Sodré nos parece pertinente, na medida em que remonta ao imaginário coletivo no berço da civilização ocidental, quando a poética, a estética e a mitologia faziam parte das experiências fundamentais na vida do cidadão, como a pedagogia, a medicina ou o culto religioso. Além disso, parecenos interessante revisitar as fontes da cultura ocidental, considerando a força das mitologias ao longo da história, justamente quando o racionalismo ocidental apresenta sinais de crise. E finalmente, é oportuno retomar hoje o enfoque dos indivíduos e dos agrupamentos sociais antigos, como pretexto para discutir os estilos das experiências individuais e comunitárias na chamada "sociedade em rede", porque nas diversas formas de empiricidades (na escola, no trabalho, no tempo livre) as novas tecnologias de comunicação ocupam o espaço público, redefinindo as maneiras de pensar, de falar e de agir dos agentes sociais, e isto nos remete a uma reflexão sobre o modo como se inscrevem os estilos de identidades e alteridades na virada do milênio.

O trabalho de interpretação das culturas é sempre arriscado quando o mesmo se propõe a um estudo comparado de domínios distintos no tempo e espaço; corre-se o risco de misturar dois pesos e duas medidas. Entretanto, entre as culturas antigas e as culturas contemporâneas existe, como denominador comum, a dimensão do simbolismo e das mitologias, que reaparecem aqui como fatores de coesão social. Em todas as épocas há sempre algo com aparência de extraordinário que seduz e fascina os indivíduos, algo que satisfaz a sua vontade de potência e de eternidade. Num ambiente midiatizado como o nosso, em que "o impossível acontece", encontramos, na ficção das telenovelas, elementos plenos de significação que animam o cotidiano dos sujeitos, estruturando os modos da atração e exclusão social.

Na idade mídia, em que a audição e a visibilidade funcionam como hegemônicos na produção e interpretação de sentido, isto é, na configuração e leitura das aparências de verdade, as mitologias se instituem fortemente pelo viés da publicidade gerada pelos meios de comunicação. O "ver" e o "ser visto" são experiências que fazem parte essencial da imaginação instituinte, desde os antigos, mas isto tem se intensificado em nossos dias.Já afirmamos que o cinema de Hollywood possui uma significação para os homens do século XX de maneira análoga ao papel desempenhado pela tragédia junto ao imaginário da antiguidade clássica. Seguindo este filão de pensamento, consideramos as telenovelas e, em última instância, as figuras e os mitos do mundo visível produzido pela mídia eletrônica como o equivalente simbólico para o imaginário coletivo do Brasil. As telenovelas, como, aliás, outros produtos da cultura de massa, contêm uma parcela importante do repertório das mitologias contemporâneas. Os mitos presentes no universo midiático-publicitário, em sua maior parte, configuram-se sob a forma dos clichês e das repetições.

Relembramos que este aspecto dos mitos como repetição consiste numa prática que permeia o longo percurso das narrativas populares, assegurando a 
sua permanência e longevidade ${ }^{8}$. Aliás, diversos estudos de antropologia ${ }^{9}$, alertam para o fato de que por trás de cada repetição e de cada clichê se agitam os arquétipos, arcanos ou imagens ancestrais, assegurando a permanência, transmissão e partilha de experiências que revitalizam o imaginário universal da humanidade. Num certo sentido, até mesmo os clichês possuem positividade e podem gerar um tipo de compreensão de detalhes essenciais dos laços comunitários, também na sociedade irradiada pelas mídias ${ }^{10}$.

3 Histórias híbridas do interior e da cidade

Desfazendo-se o "sonho feliz de cidade", numa época em que a modernidade e suas promessas de felicidade apresentam sinais de desgaste, os sujeitos buscam uma "cultura da paz"11, fugindo da insegurança causada pela violência cotidiana dos centros urbanos.

O Brasil experimentou as sensações da modernização nos anos 20, passou pelo surto desenvolvimentista nos anos 50 e vivenciou a irradiação do "milagre econômico" nos anos 70; em meio às crises e oportunidades, parece ter amadurecido, nos anos nublados da década de 80 , sentindo na pele as conexões com a modernidade ocidental e suas fraturas; nos anos 90, experimenta também novas tensões e conflitos, assim como novos modos de territorialização e sociabilidade, que passam pelo crivo das redes midiáticas.

Um dado importante para uma sociologia da comunicação diz respeito às novas formas e direções dos movimentos migratórios; do campo para as cidades, assim como o retorno da cidade ao campo, isso implica a imbricação dos espaços e tempos dos indivíduos, com repercussão marcante no imaginário coletivo. Todos estes espaços e tempos históricos são revisitados pelas mídias e redistribuídos socialmente, de forma a estabelecer linhas de identificação com as novas gerações, que reinventam e atualizam as experiências dos seus predecessores.

As mídias contam com recursos humanos e tecnológicos para atender a uma vasta diversidade de público, incluindo as gerações informadas pelos diferentes recursos comunicacionais, e busca também realizar os seus produtos com a atenção voltada para os tipos de público que se reconhecem nas simulações da vida no interior, no sertão, no campo e na cidade. Procuramos discutir o modo como, na sociedade globalizada, a reconstrução das cidades pelas mídias permite uma decifração do cenário cotidiano por meio de uma poética tecnológica que transcende as fronteiras do regional e do universal, do local e do global, do intimista e do cosmopolita.

As narrativas geradas pelas mídias, representadas pela profusão de livros, discos e vídeos, produziram um tipo de imaginário social híbrido. Canclini mostra essa nova modulação das "culturas híbridas" e suas ressonâncias nos diferentes espaços do globo ${ }^{12}$. O velho e o novo, o arcaico e o ultramoderno, o artesanal e o cibernético estão imbricados nos atuais processos de trocas simbólicas. O desafio que se apresenta, neste contexto, é interpretar como os indivíduos se atualizam e interagem junto aos seus semelhantes, reinventado os laços sociais, realizando os desejos e necessidades, e exercendo o direito de decisão e de participação na vida pública.

\section{Mediações culturais: de Cabral a Blade Runner}

A segunda metade do século $X X$ é memorizada como um período em que - Brasil ganhou a aparência de um país urbano, industrializado e irrigado pela cultura das mídias. Isto alterou bastante a sensibilidade dos indivíduos, suas maneiras de se conduzir na vida pública, de se relacionar e de intervir na construção do cotidiano. As gerações, cuja maturação 
se desenvolveu neste espaço de tempo, neste "novo mundo" infestado pelos meios de informação e comunicação, experimentaram mudanças fundamentais nas percepções de si próprios, do mundo social e do mundo cósmico.

Apontamos há pouco os traços mais intimistas, de cordialidade e sociabilidade na experiência imaginária e vivencial dos seres influenciados pelos valores das gerações mais antigas. Há apenas três décadas, os sujeitos formavam a sua imaginação do mundo a partir das referências da vida no campo, no contato com as arborescências da natureza, do mundo agrário, num tempo em que a publicização da vida não era tão eminente. $\mathrm{O}$ intimismo era uma regra na sociedade brasileira dos anos 50/60.

Com a urbanização, o crescimento das cidades e com o melhoramento dos sistemas de transportes e de informação assistimos a uma transformação nas estruturas da vida cotidiana nas décadas $70 / 80$, e conseqüentemente a formação de uma nova mentalidade urbana. As mídias têm uma contribuição incisiva neste processo difundindo novos hábitos de consumo, fabricando desejos e necessidades e criando a figura pública do cidadão. A exigência da cidadania é contemporânea à evolução das cidades, quando emergem novos dispositivos legais e novos contornos do espaço público, possibilitados também pelas redes e tecnologias de interação virtual, o que se distingue com visibilidade a partir da década de 90.

Tudo isso vai se inserindo e transformando o mundo simbólico, que possui uma significação mitológica importante na existência dos contemporâneos. Para entender este novo "mundo visível", para compreender o seu modo de funcionamento, os seus efeitos, a maneira como absorve as mediações realizadas pelos indivíduos, recorreremos à imaginação mitológica universal que tem orientado os povos e culturas ao longo da história da cultura.

A televisão, como uma espécie de "máquina de fazer deuses", rememoriza e reconstrói os temas míticos ancestrais. Por exemplo, na fabricação das imagens da metrópole, a ficção na TV, para seduzir eficazmente os telespectadores, remonta aos símbolos de força, velocidade, gigantismo e verticalidade. Nas ciências da interpretação dos mitos, encontramos leituras que recorrem à figura do herói mitológico Prometeu, aquele que roubou o fogo dos deuses para entregar aos humanos, como uma estratégia de compreensão dos sujeitos orientados pelas promessas de felicidade gerada pelo progresso. O progresso material e tecnológico das cidades, com os seus vidros, ferros e fortalezas de concreto, prometendo segurança, privacidade e prestígio, aparece hoje, no século XXI, como um sonho de felicidade. Percebemos que este é um tipo de mitologia, aparece como um mundo a ser atingido, uma Canaã pós-moderna. Nesse contexto, a América aparece como o modelo "concretizado" deste universo idealizado; o sonho americano permanece vivo, como uma referência para o ocidental contemporâneo e o seu desejo de obtenção da glória terrena; embora, antagonicamente, esta mesma América se inscreva sob o signo do limite e da finitude. Neste sentido, o livro de Fukuyama O Fim da História e o último homem ${ }^{13}$, serve como emblema da razão sensível na transição entre os séculos $X X$ e XXI. Num outro registro, há um trabalho interessante de Brissac Peixoto, Cenários em Ruínas ${ }^{14}$, em que, pela interpretação do cinema, da publicidade, da paisagem urbana das cidades americanas, o filósofo descreve o estilo dos seres urbanos e seu itinerário no mundo pós-moderno, acentuando suas formas de solidão e sociabilidade. No cinema, o filme Blade Runner, o Caçador de Andróides ${ }^{15}$ é bem significativo do "espírito do tempo" que rege parte do imaginário coletivo do fim de milênio. De certo modo, Blade Runner 
traduz a alegoria proposta por Walter Benjamin, mostrando uma visão da história como um acúmulo de ruínas. A tradução literal deste roteiro adaptado do romance de Philip Dick, Blade Runner, exprime a condição dos indivíduos do século $\mathrm{XXI}$, ou seja, "escapando por um fio". Mas por outro lado, é pertinente notar que a imaginação do futuro em Blade Runner, servindo como referência para um percentual importante das jovens gerações no planeta, remete a um certo amadurecimento, à perda de uma nostalgia e ao fim da idéia de felicidade escondida no futuro. Se há um aspecto pleno de positividade em Blade Runner, este reside em apontar para uma afirmação do presente; então, numa ambiência, aparentemente regida pelo signo de Prometeu, o deus Dionísio ressurge reafirmando o lado vitalista e orgânico do cotidiano.

As imagens míticas do cinema e da televisão refletem (e intensificam) esta dimensão da realidade que se tornou urbana, de aparência excessiva e abundante. Mas convém notar que as modulações do urbanismo, do progresso e da modernidade se expressam diferentemente em cada parte do globo e, igualmente, estas noções são percebidas e assimiladas pelos indivíduos e tribos de maneiras distintas. É interessante observar como as leituras e mediações dos leitores e telespectadores em culturas diferentes, como as latinas, assimilam, desmontam e reconstroem as significações propostas pelas mídias, incluindo aí o cinema e a televisão, de acordo com os seus próprios hábitos culturais, considerando as próprias influências ancestrais e históricas do imaginário mítico latino-americano.

Como mostra o sociólogo Serge Grunzinsky, no livro A Guerra das Imagens, De Colombo a Blade Runner ${ }^{16}$, a recepção do filme Blade Runner representa uma atualização no "diálogo" entre as culturas nativas e as culturas estrangeiras, num processo que se iniciou desde a chegada de Colombo às Américas. Grunzinsky discute como os "nativos" sempre se portaram "carnavalescamente", invertendo, mediando e adequando as propostas do "imperialismo sedutor", como exemplifica a preservação do culto de Nossa Senhora de Guadalupe, padroeira do México, que resiste por meio de sincretismos inteligentes e criativos, reciclando os objetos e símbolos produzidos pelas indústrias culturais. 0 repertório latino-americano pode ser forte o suficiente até mesmo para fazer frente às formas de colonização das imagens do futuro.

De modo instigante observamos a aproximação dos enfoques de Canclini, Grunzinsky e Jesús Martín-Barbero ${ }^{17}$ focalizando a agilidade das mediações realizadas pelos indivíduos no encontroconfronto das distintas interfaces culturais, e isto nos estimula a compreender a interrelação nos diferentes recortes simbólicos que se perfazem também nos espaços urbanos contemporâneos das cidades do Brasil.

Em suma, parodiando Grunzinsky, sem perder de vista o fio condutor do seu trabalho, atento aos modos de colonização e às mediações culturais, pensamos no estilo de recepção cultural dos brasileiros, cujas estratégias de comunicação demonstram estilos específicos de apropriação e carnavalização das imagens, de Cabral a Blade Runner.

Cumpre decifrar as estratégias de comunicação, que se mantêm ativas na agilidade de transmissão da experiência em conexão com as formas culturais emergentes. Por este prisma percebemos como se forjam os tipos de identidade, identificação, comunicabilidade e sociabilidade, na era da informação.

Atualização dos mitos na cultura pop da televisão

$\mathrm{Na}$ televisão, simulando a geometria das selvas de pedra das grandes cidades, as ficções exibem as cópias, próteses e clonagens, o amontoado e a profusão 
de objetos e instrumentos que atestam a opulência material da civilização e do progresso. Na mitologia antiga, a figura de Proteu, com suas metamorfoses e multiplicações, traduz uma psicologia das profundezas que percebe a vontade de eternidade dos homens, o desejo de participarem da reprodução, duplicação e clonagem do mundo, passando de criaturas a criadores. A máquina fotográfica, o xerox, o gravador, a filmadora e o computador são dispositivos que revelam esta afinidade dos homens com Proteu. Se considerarmos o processo de clonagem, possibilitado pela engenharia genética, como uma experiência que repercute nas maneiras dos indivíduos formarem as idéias sobre si e sobre o mundo à sua volta, percebemos um certo retorno da força mitológica de Proteu.

Os sonhos de riqueza material não fazem os indivíduos esquecerem a sua condição de finitude, os afetos e desafetos do espírito, a sua natureza biológica, orgânica e pulsional. Esta dimensão da experiência vivencial dos seres possui a sua tradução na mitologia antiga, pelo viés do culto e do rito do deus Dionísio. O retorno do hedonismo, do misticismo religioso, do erotismo e da liberalização dos costumes, com seus hibridismos e interpenetrações atestam o retorno de Dionísio na idade mídia.

O nosso argumento voltado para a compreensão do "caos e a poética da cidade" busca descrever as formas das vontades, desejos e necessidades que movem os indivíduos e grupos na paisagem urbana, busca compreender os modos de exclusão e de agregação dos sujeitos nas cidades de pedra, assim como as suas projeções na ficção televisiva. Para isso remontamos ao mito de Dionísio, que exprime uma decupagem religiosa, permitindo-nos apreender as formas do hedonismo e do êxtase numa sociedade cujos parâmetros de racionalidade entraram em declínio, e cujo espírito comunitário se realiza por vias que atualizam os mitos antigos.

É pertinente recorrer às significações dessas figuras míticas e lendárias também porque há um acervo considerável de estudos, relatos, objetos artísticos, pinturas, livros, peças e filmes que atestam a permanência das diversas interpretações dos estados da alma, tendo como orientação leituras que exprimem dimensões importantes do imaginário ocidental. Numa abstração mais rigorosa e inspirada no mundo panteísta dos antigos, podemos recorrer à imaginação mitológica, como se recorre à imaginação criativa de Dante, Shakespeare, Cervantes ou Fernando Pessoa, para compreender mais sobre os seres, o seu espírito de agregação, sobre o mistério da sua significação no mundo, sobre os seus modos de comunicabilidade. Deste modo, as narrativas não têm necessariamente que explicar o mundo dos seres, da sociedade e da natureza; elas, por outro lado, podem estimular a faculdade dos indivíduos de perceber, interpretar e transmitir as experiências e vivências do mundo. As narrativas de ficção, marcadas pelos enunciados do real histórico e da imaginação simbólica, seduzem os indivíduos pela estratégia de recuperação de um tempo mítico, em sintonia com a expectativa dos leitores e telespectadores.

$\mathrm{Na}$ ficção televisiva do Brasil há realizações, que apresentam aspectos importantes do imaginário coletivo, que identificamos com as mitologias grecolatinas, e a maneira como são feitas as adequações dessas mitologias passam pelo crivo dos códigos culturais brasileiros. Os simulacros de imagens, sons e textos difundidos pelas redes de comunicação performatizam a atualização dos mitos remotos e ancestrais. No universo imaginário dos brasileiros os arquétipos antigos, os arcanos da imaginação terrena, os grandes símbolos universais são filtrados pelos códigos da religião cristã ou dos paganismos, enfim, das orientações espiritualistas de diversos credos. Mas 
são temperados pela sensualidade que faz parte das heranças genéticas, históricas e culturais; são hibridizados pelo hedonismo atual sob os matizes dos trópicos. Neste sentido, as interpretações de Gilberto Freyre e suas "teorias das mestiçagens" e "interpenetrações culturais" permanecem como um referencial antropológico adequado também para entendermos o ethos do brasileiro, no contexto sociocultural das redes e mídias ${ }^{18}$. O dionisíaco brasileiro, bem descrito na sociologia de Gilberto Freyre, projetado na literatura dramatúrgica de autores como Ariano Suassuna (e suas adaptações para o cinema) e declamado nas canções urbanas dos artistas da música pop, persiste com desenvoltura no ambiente concreto da paisagem urbana.

Muitas telenovelas, de certo modo, anteciparam as experiências urbanas junto ao imaginário coletivo do Brasil. Por exemplo, antes do divórcio, do uso dos contraceptivos e preservativos, a televisão já estimulava os indivíduos a novas percepções de si, da sociedade e da cultura. Estas telenovelas situam uma espécie de pré-história da poética urbana brasileira, no contexto das artes visuais de massa. Desmontando a estética dos cartões postais do Rio de Janeiro, muitas telenovelas propuseram formas contemplativas, dos arrabaldes da metrópole, muito além de uma visão maquiada da "cidade maravilhosa". Buscando fisgar o "gênio do lugar" que rege as razões e sensibilidades de uma metrópole como São Paulo, diversas ficções televisivas propuseram uma tradução poética do caos urbano desta cidade.

Há telenovelas que irradiam uma estesia das perturbações sociais numa metrópole, permitindo-nos apreender - cotidiano das grandes cidades. Consideramos o espaço urbano organizado sob o signo de Apolo ${ }^{19}$, onde tudo se mostra por meio de uma estética agradável aos olhos e de contornos claros e bem definidos.

Ao lado deste perfil apolíneo da cidade industrial, percebemos a presença de Prometeu ${ }^{20}$, cujo mito do progresso, do desenvolvimento científico e tecnológico seduz a sensibilidade urbana. Seguindo as inspirações de uma imaginação mitológica para compreender o "espírito das cidades", reencontramos a figura de Proteu ${ }^{21}$, entidade que encarna a reprodutibilidade, com várias faces, gerando mercadorias em profusão, criando a panóplia dos objetos, o excesso da grande cidade. Neste ambiente de recorte linear, de aço e fogo restaurador, das múltiplas próteses, a potência dionisíaca virá arrebentando a harmonia em pedaços.

Neste sentido é sintomática a abertura da telenovela A Indomada (1998), cujas imagens traduzem uma atualidade do imaginário mítico, em que uma ninfa, encarnada pela atriz Maria Fernanda Cândida, escapa com agilidade da súbita aparição de prédios que emergem das profundezas da terra, atingindo os céus. Aquela abertura torna evidente a presença de elementos míticos e transcendentais na construção cibernética que norteia a estética pós-moderna da telenovela. Neste encontro-confronto entre os seres e as cidades de pedra, de ferro e de vidro, podemos ler uma breve aparição do deus Dionísio, que surge imprimindo sua forma orgânica, selvagem e vitalista no ambiente da cidade.

Telenovelas mais antigas como Selva de Pedra (1972), O Espigão (1974) e O Grito (1976) exibem as formas da anomia social, mas também da sociabilidade nas grandes metrópoles. Mostram as formas de estranhamento do humano na concretude urbana, mas distinguem uma delicadeza na descrição das sensações, afetos e sentimentos. Há formas importantes de traduções estéticas, nas ficções fabricadas, a partir de impressões das capitais e das grandes cidades do Brasil. Ali, produzemse os simulacros das selvas de pedra, das cidades poluídas; mostram-se, igualmente, o desemprego, a violência 
urbana, a superpopulação e o crescimento desordenado nas ficções. Entretanto, são exibidas também as imagens da grande cidade como um espaço dos encontros furtivos, dos paraísos artificiais, dos fantasmas eróticos das tribos urbanas; há ficções importantes movidas pelo ímpeto de desvelar o enigma da natureza e o espírito das cidades de pedra.

Pode ser recorrente, para uma apreciação estética dos centros urbanos vistos pela televisão, remontar às contribuições estéticas da poesia concreta. O concretismo trata-se de um estilo, cuja estratégia sensível de retomar os signos dispersos na anomia da cidade e reorganizá-los num sentido diferente goza da sabedoria de traduzir bem o caos urbano, a dimensão geométrica e cerebral da ecologia urbana. A sensibilidade cosmopolita do concretismo apreende, desenha e devolve à percepção pública as formas de solidão e solidariedade nas metrópoles.

A captação dos estilos de neurose e felicidade na grande cidade, realizada pela estética concretista, misturando visões e mitos urbanos, impregna de humanidade o cotidiano acústico, visual e sensitivo da cidade. Este é também um estilo de carnavalização das imagens, realizado, anteriormente, num outro registro, pela antropofagia modernista e, posteriormente, pela estética do tropicalismo, como hoje pelas reinvenções musicais do movimento mangue-beat, do Recife ${ }^{22}$.

6 Cidades ocultas do Brasil, no cinema e na televisão

Diversos recortes e interpretações das grandes cidades funcionaram como sugestões valiosas para os dramaturgos e escritores da televisão. Por exemplo, o dramaturgo Jorge de Andrade, na telenovela $\mathrm{O}$ Grito, se apoiou num roteiro instigante. Em seu objetivo de construir um retrato da cidade de São Paulo, empreendeu um mergulho profundo no inconsciente coletivo da cidade.

$\mathrm{O}$ cotidiano de uma metrópole onde vivem milhões de pessoas, experimentando diversas formas de afetos e exclusões, neuroses e formas distintas de sociabilidade, serve como ponto de partida para uma apresentação "realista" da cidade, que permite flagrantes dos seres, em suas experiências públicas e intimistas. O enfoque desta telenovela libera estímulos para uma antropologia urbana, interessada na dimensão interior (e invisível das cidades) e também na sua dimensão exterior, pública e visível. O Grito é uma ficção que se constrói no espaço estreito entre o mundo de vigília e o mundo onírico. Nesta construção imaginária de São Paulo, o sonho feliz de cidade, a altitude, a parte aérea do cotidiano urbano, tem em contrapartida o pesadelo, o baixo, a parte subterrânea do social. Os sonhos e pesadelos de uma criança que acorda no meio da noite aos gritos agitam-se ruidosos na cabeça dos telespectadores; eles despertam reminiscências que se escondem por trás dos atos de fala, dos gestos, dos códigos de linguagem. A estética da ficção se faz em abismo; a apresentação do social, em O Grito, é abalada por uma sonoridade estranha que invade todos os espaços. O ruído gerado pela comunicação da telenovela, por meio do "grito", desperta os sujeitos para uma acústica da cidade real, repleta pela sonoridade dos momentos de tristeza e de felicidade.

A dureza e verticalidade de São Paulo se mostram aqui, em seus pontos de fratura. Esta cidade tão concreta, masculina, fechada, é perturbada por um grito que irrompe no silêncio da noite; o rugido ensurdecedor de Dionísio ecoa quebrando a harmonia circundante. Este tema, de tratamento difícil, incomodou o público habituado com a exibição apolínea das imagens maquiadas. Entretanto, esta é uma ficção estranha que permanece ativa na imaginação das telenovelas: da inquietação e da dor, o "mal" se faz poesia. Captamos, nesta narrativa insólita, um conjunto de imagens que se exprime como 
os versos da canção, da "dura poesia concreta" no coração da selva de pedra.

$\mathrm{Na}$ contemplação de Dionísio na grande cidade, seguimos as pistas deixadas pelas telenovelas brasileiras em seu longo percurso de 40 anos. Esperamos, assim, traduzir, de modo aproximado, a fotografia do Brasil urbano, das "selvas de pedra", em suas diversas modulações nas telenovelas. Algumas questões se agitam impertinentes, na medida em que buscamos compreender as "novas" mitologias (o que abrange o universo da ficção televisiva). Seguindo a "razão sensível" de Gaston Bachelard e sua epistemologia que nos instiga a considerar a "intuição do instante", encontramos emblemas, signos e sinais no conjunto de enunciados, que nos permitem a presença de Dionísio no mundo tecnológico habitado por Proteu, Apolo e Prometeu. Reencontramos na ficção, numa outra dimensão mitológica, a praça de Dionísio, o deus da festa coletiva, do êxtase, da morte e do renascimento na roda-viva do mundo urbano.

Um primeiro enfoque apreende a cidade pós-moderna no talhe das suas construções para o alto ou nas suas formas lisas, geométricas e concluídas que, definindo a hegemonia do olhar, caracterizam um mundo apolíneo. Mas os espaços de autonomia, de harmonia e de individualização característicos deste mundo apolíneo, são permanentemente perturbados pela presença intempestiva, ruidosa e tribal do espírito dionisíaco.

No espaço urbano, cujas novas formas de individualização parecem majoritárias, encontramos a surpreendente aparição de novas relações sociais que redefinem a paisagem. Esta aparição não exprime sempre as formas (simpáticas) da agregação social; revela de diferentes maneiras as pulsões agressivas que povoam o espaço urbano; citamos, a propósito, os bandos, as gangues, as novas tribos que se disputam nas ruas espalhando o perigo no espaço de "pureza" das cidades: os shopping centers, supermercados e aeroportos têm de conviver com os ruídos, odores e visões agressivas do social. Enfim, estas "novas" formas de "sociabilidade" estão presentes também na ficção televisiva.

A visão de Walter Benjamin sobre a grande cidade, a partir dos poemas de Baudelaire, é estimulante para repensarmos a presença do dionisíaco na grande cidade. O seu estudo sobre As passagens de Paris $^{23}$, fornece-nos as bases para uma compreensão social da estética da cidade. A interpretação de Benjamin consiste uma hermenêutica, sobretudo, poética, no sentido que ele "arranca" as imagens, figuras e objetos da sua significação muda e funcional, e as recobre com uma "aura" que emana investimentos afetivos. Os negócios da moda, as exposições universais, as imagens em movimento dos trens e do cinema, a iluminação a gás, a circulação de figuras como o "jogador", o "colecionador" e o "flanador" apresentam as imagens dionisíacas num mundo que parece engolido pelo progresso, mas que não pode pertencer a Prometeu.

Leitor de Marx, Proust, Brecht, Scholem, Kafka, etc., Benjamin nos deixou um legado que nos incita a interpretá-lo como um tipo de "materialismo místico", uma experiência que compreende a riqueza do mundo em suas aparências e visibilidades.

A leitura de Benjamin nos estimula a contemplar as grandes cidades e a sua inscrição no imaginário das telenovelas. Tomamos de empréstimo as imagens benjaminianas para pensar uma estética da cidade de São Paulo. Reencontramos as imagens dionisíacas na apresentação de São Paulo, em princípio na poética musical de Caetano Veloso, sob a forma do sugestivo poema Sampa, que participa com freqüência das trilhas sonoras da ficção televisiva.

Os versos de Sampa desvelam uma sensibilidade trágica e entusiasmada, um olhar que apreende a conjugação das formas duras da poesia concreta e as formas do sensível que cimentam a atração social no corpo da 
cidade.

O cinema, nos anos 80 , realizou um filme importante, em São Paulo, chamado Cidade Oculta. Nesta ficção paulista se projetam as tribos urbanas, que circulam num ambiente excitado pelas bandas de rock, cocaína, estética neogótica, uma expressão dos novos dândies sob o céu sombrio da cidade. O visual dos arranhacéus, os shopping centers em aço e vidro e o desenvolvimento vertiginoso de uma cidade que não pára de crescer cedem lugar, em Cidade Oculta, a uma estética que contempla profundamente a superfície de São Paulo sem maquiagem. Arrebentando o espaço linear da grande cidade pósindustrial, estruturada pelos negócios econômicos, percebem-se as tribos dos punks que transitam entre os officeboys, yuppies, executivos e traficantes. Jogadores, policiais corruptos, bandidos, artistas e amantes da música compõem o quadro alegórico desta ficção que mostra a fúria de Dionísio, desordenando as regras sociais e refazendo alianças imprevistas. A estética de Cidade Oculta permanece, na história da cultura audiovisual do Brasil, como uma referência importante, que norteará novas realizações .

Notas

1 Cf. HALL, S. A identidade cultural na pós-modernidade. Rio de Janeiro: DP\&A Ed., 2000.

2 Sobre as formas "reativas", consultar os trabalhos de G.DELEUZE \& GUATTARI, F. Mil Platôs, Capitalismo e Esquizofrenia. São Paulo: Ed. 34, 1995, 3 vol. De modo específico, os filósofos se referem ao termo "reativo", em analogia à noção militante de "reacionário", em voga nos anos 60/70. Encontramos nas telenovelas e minisséries da Rede Globo inúmeros casos de personagens e situações mostrados sob a forma de simulacros "reativos", em que os negros, índios, gays, pobres e nordestinos são apresentados de forma preconceituosa, folclórica ou excludente. No outro extremo, há positivamente, exemplos de personagens e situações descritos de maneira correta, em sua intensidade e complexidade, 0 que permite ao telespectador-leitor um tipo de reflexão, e eventualmente, a formação de uma consciência crítica da realidade, atenta à aproximação das fronteiras que recortam as diferenças nos espaços e tempos do cotidiano.

3 KRISTEVA, J. Étrangers à nous-même (Estranhos a nós mesmos). Paris: Seuil, 1986.

40 "princípio dialógico" é uma noção presente nos estudos de Mikahil Bakhtin, que se presta a um debate sobre Comunicação, Linguagem e Sociedade. Refere-se à pluralidade de enunciados que constituem a comunicação social e pode ser estudado nas seguintes obras: BAKHTIN, M. A cultura popular na idade média e no renascimento. 0 contexto de François Rabelais. S. Paulo: UnB/Hucitec, 1987; _ Problemas da Poética de Dostoiévsky. S.Paulo: Forense Universitária, 1981; _ TODOROV, T. Mikhail Bakhtine, Le principe dialogique. Paris: Seuil, 1981.

5 Relembramos a propósito, "Tenda dos Milagres" (Aguinaldo Silva e Regina Braga, 1985), "O Tempo e o Vento" (Doc Comparato, 1985), "Grande Sertão Veredas" (Walter George Durst), "O Pagador de Promessas" (Dias Gomes, 1988), "O Primo Basílio" (Gilberto Braga e Leonor Basséres, 1988), "Capitães de Areia" (José Louzeiro e A.C. Fontoura, 1989), "Riacho Doce" (Aguinaldo Silva e Ana Maria Moretzhon, 1990), "O Sorriso do Lagarto" (Walter Negrão e Geraldo Carneiro, 1991) e "Memorial de Maria Moura" (Jorge Furtado, Carlos Gerbase e Ênio Povoas, 1994). Ver a propósito a tese de Narciso LOBO. Ficção e Política, 0 Brasil nas Minisséries. Manaus: Editora Valer, 2000.

6 Sobre as relações entre as telenovelas e as mitologias, consultar COSTA, C. A milésima segunda noite, Da narrativa mítica à telenovela - Uma análise estética e sociológica. S. Paulo: Annablume/FAPESP, 2000.

7 SODRÉ, Muniz. Máquina de Narciso, Televisão, Indivíduo e Poder. Rio de Janeiro: Achiamé, 1984.

8 Sobre a repetição no contexto das telenovelas e das culturas populares, consultar BORELLI, Sílvia Helena. "Novela é coisa de mulher?". Colóquio apresentado no GT Ficção Televisiva e Seriada, no XXIII Congresso Brasileiro de Ciências da Comunicação, Manaus, 02 a 06 de setembro de 2000. (A disposição no CD da INTERCOM 2000). 
9 Ver os estudos de Michel MAFFESOLI, O Tempo das Tribos (1987), No Fundo das Aparências (1996) e Elogio da Razão Sensível (1998).

10 Cf. PAIVA, Rachel. 0 Espírito Comum, Comunidade, Mídia e Globalismo. Petrópolis: Vozes, 1998.

11 A tomada de consciência diante do problema da violência tem gerado preocupações e propiciado debates sobre "cultura da paz", como expressa X Encontro LatinoAmericano de Faculdades de Comunicação Social, FELAFACS/ABECOM, realizado em São Paulo, de 23 a 26 de outubro de 2000, que elegeu como tema "Comunicação e Cultura da Paz".

12 CANCLINI, Nestor Garcia. Culturas Híbridas. S. Paulo: Edusp, 1998.

13 FUKUYAMA, 0 fim da história e o último homem. Rio: Rocco, 1992.

14 BRISSAC PEIXOTO, N. Cenários em Ruínas. S. Paulo: Brasiliense, 1986.

15 Cf. Blade Runner, 0 caçador de Andróides. Dir. Ridley Scott, EUA, 1982, roteiro adaptado do livro de Philip K. DICK, "Do Androids Dream of Electric Sheep?" (Os Andróides sonham com Carneiros Elétricos?) Rio: Francisco Alves, 19_.

16 GRUNZINSKY, S. La Guèrre des Images, 1492-2014 - De Colombo a Blade Runner. Paris: Fayard, 1995.

17 MARTín-BARBERO, J. De los medios a las mediaciones. Barcelona: Gustavo Gilli, 1987; ver igualmente a coletânea organizada por MARQUES DE MELO, J. Teoria da Comunicação, Paradigmas Latino-Americanos. Petrópolis: Vozes, 1999; MARQUES DE MELO, J; ROCHA DIAS, P. (org.) Comunicação, Cultura, Mediações - 0 percurso intelectual de Jesus Martin Barbero. São Bernardo do Campo: UMESP, 2000.

18 FREYRE, G. Casa Grande e Senzala. Rio, José Olympio, 1969.

19 Sobre 0 mito de Apolo consultar, KERÉNYI, K. Apollon. Vienne, 1937; BRANDÃO, Junito. Mitologia Grega. Petrópolis: Vozes, 1998; GRIMAL, P. Dicionário da mitologia grega e romana. Rio: Difel, 1993.
20 Acerca do mito de Prometeu, sugerimos a leitura de SÉCHAN, L. Le mythe de Prométhée. Paris: PUF, 1982 (1951); TRIOMPHE. Promethée et Dionysos ou la Grèce à la lueur des torches. Strasbourg: P.U.S., 1992.

21 Sobre 0 mito de Proteu, consultar BRANDÃO, Junito. Mitologia Grega. Petrópolis: Vozes, 1998; GRIMAL, P. Dicionário da mitologia grega e romana. Rio: Difel, 1993. Para uma atualização do mito de Proteu na sociedade consumo, verificar BAUDRILLARD, J. A sociedade de consumo. Lisboa: Edições 70, 1981/ Rio: Elfos, 1995; _ A transparência do mal, Ensaios sobre os fenômenos extremos. Campinas: Papirus, 1990; __ Simulacros e Simulação. Lisboa: Relógio D'água, 1991.

22 Sobre as experiências do movimento mangue-beat, conferir um interessante sítio na Internet, com imagens, sons e textos in Erro! A origem da referência não foi encontrada.

$23 \mathrm{Cf}$. BENJAMIN, W. Obras Escolhidas, Vol. III, Charles Baudelaire, Um lírico no auge do capitalismo. S. Paulo: Brasiliense, 1989; __ A modernidade e os modernos. Rio: Tempo Brasileiro, 1975; ROUANET, S. P. "Benjamin, o falso irracionalista" e "As galerias do sonho" in As razões do iluminismo. São Paulo: Companhia das Letras, 1987; Sobre as relações entre experiência e comunicabilidade, ver BENJAMIN, W. "O Narrador" in _ Obras Escolhidas. S. Paulo: Ed. Brasiliense, 19_. Particularmente, no que concerne aos estudos de comunicação, consultar o teórico da comunicação RODRIGUES, A. Cultura e Comunicação, A experiência cultural na era da informação. Lisboa: Presença, 1994. 